\title{
Horse Sarcoid
}

National Cancer Institute

\section{Source}

National Cancer Institute. Horse Sarcoid. NCI Thesaurus. Code C134995.

A fibroblastic tumor that occurs in the skin of a horse. 